\title{
III
}

\section{MEMÓRIA E ESQUECIMENTO NA HISTÓRIA DA EDUCAÇÃO: OS GRUPOS ESCOLARES DE MEDIANEIRA (1950-1970) ${ }^{*}$}

\author{
Sander Fernando de Paula
}

\section{INTRODUÇÃO}

A memória vem se colocando como um foco importante nos estudos contemporâneos. O termo memória, originalmente formulado pelo sociólogo francês Maurice Halbwachs (2003), é definido pelo autor como sendo o processo social de reconstrução do passado vivido e experimentado por um determinado grupo, comunidade ou sociedade. Assim, memória e história são processos sociais, construções dos homens que têm como referência as experiências individuais e coletivas inscritas nos quadros da vida em sociedade.

A pesquisa acerca dos grupos escolares na região Oeste do Paraná, a partir de seus determinantes políticos, sociais e econômicos, abre caminhos para novas investigações, contribuindo para as pesquisas da História da Educação. Fomentar as discussões a respeito dessa modalidade de ensino, que, apesar de ter obtido espaço expressivo dentro do meio acadêmico nas últimas décadas, ainda é um campo pouco explorado, possibilitando indagações que propiciam a análise do processo de desenvolvimento social e educacional dessas instituições, permitindo um diálogo pleno entre a academia e a comunidade.

Podemos também revisitar a memória histórico-educacional mediante coleta de dados revisão literária e documental de obras, periódicos e arquivos. A memória também é relacionada em compreender como o sistema do capital tem se servido da educação institucionalizada para produzir/reproduzir ideologias via processo de agenciamento da memória social e como esse processo se afirma enquanto mecanismo de perpetuação das contradições peculiares do metabolismo capitalista. Ao mesmo tempo, em que essa própria educação pode se apresentar, de maneira contraditória, uma produção da memória social alternativa, contra-hegemônica.

No sentido de preservar esta memória, surgiram nos últimos anos diversos estudos sobre a História da Educação na região Oeste do Paraná, com

*DOI - 10.29388/978-65-86678-77-2-0-f.38-52 
o intuito de preservar as fontes e arquivos que guardam a história e a memória oral e escrita das instituições. Pesquisadores, professores e a comunidade vêm reunindo esforços na catalogação de documentos, buscando proteger a história educacional.

Citamos aqui as contribuições do Grupo de Pesquisa História, Sociedade e Educação no Brasil, GT Oeste do Paraná (HISTEDOPR) ${ }^{1}$, que desde 2003, busca o levantamento, a organização e a catalogação de fontes primárias e secundárias para a História da Educação na Região Oeste, resultando atualmente em centenas de trabalhos entre artigos, monografias e dissertações.

O mesorregião Oeste do Paraná é um vasto território, formado por municípios que em sua maioria, originaram-se da colonização a partir dos imigrantes sulistas durante o século XX, vindo de Santa Catarina e Rio Grande do Sul. Assim, como a urbanização fizeram parte do intuito de desenvolvimento dos imigrantes, a educação também ganhou espaço, de forma branda, mas essencial às necessidades de escolarização dos filhos, sendo a gênese dessa modalidade de ensino denominada de grupos escolares.

O presente artigo discorre sobre as relações entre memória e esquecimento na pesquisa de fontes e arquivos nos estudos dos grupos escolares na Região Oeste do Paraná. Delimitamos a pesquisa, focando os estudos aos grupos escolares do município de Medianeira, determinando o recorte histórico durante o período que corresponde de 1950 - quando do início da colonização das terras - à 1970 - período onde os grupos escolares passaram por transformações político-pedagógicas e posterior extinção pelo governo através da lei 5692/71. Trata-se de apontamentos iniciais da pesquisa de Mestrado em Educação intitulada: "História e Memória da Educação na Região Oeste do Paraná: a Constituição dos Grupos Escolares no Município de Medianeira (1950-1970)" em andamento.

Este capítulo está organizado em três momentos. No primeiro, abrimos considerações sobre memória dentro das pesquisas em história e historiografia. No segundo momento, analisaremos a memória e esquecimento

\footnotetext{
${ }^{1}$ O HISTEDOPR é um grupo de pesquisa em "História, Sociedade e Educação no Brasil", com sede na Universidade Estadual do Oeste do Paraná - UNIOESTE -, na Região Oeste do Paraná. Está vinculado ao Grupo de Pesquisa em "História, Sociedade e Educação no Brasil" - HISTEDBR (www.histedbr.fae.unicamp.br), que tem abrangência nacional e organiza-se por meio de Grupos de Trabalho (GTs) regionais. O HISTEDOPR tem como um de seus principais objetivos, promover o "Levantamento, a Organização e a Catalogação de Fontes Primárias e Secundárias para a História da Educação na Região Oeste do Paraná", contribuindo assim, com os demais grupos que integram o HISTEDBR, para ampliar o levantamento, a organização e a catalogação das fontes em âmbito nacional.
} 
nas relações com a pesquisa de fontes para a história da educação e, no terceiro, abordaremos a pesquisa dos grupos escolares de Medianeira.

\section{BREVES CONSIDERAÇÕES SOBRE MEMÓRIA}

A pós-modernidade vem criando novos significados sob a égide das novas tecnologias e um certo esvaziamento do ideário de memória. Nesse sentido, as "novas abordagens" sobre a História procuram subtrair-lhe a dimensão do conflito, homogeneizando as relações sociais, em esforço evidente para omitir a exploração e a dominação no passado, de forma a naturalizar a exploração e a dominação de hoje. Não por acaso, o desencanto com o "progresso" e a crise dos paradigmas da racionalidade gerou posturas que procuraram demonstrar a "impossibilidade" de se conhecer o passado.

Tal movimento vem mostrando uma realidade de fragmentação e segmentação da informação, pelo entrelaçamento entre cultura e comunicação, e da valorização das imagens, onde o "novo", de hoje, torna-se o "velho" de amanhã. Frente a este contexto, novas tendências de investigar e pensar a realidade são anunciadas, por meio de um processo de desideologização do passado.

A rigor, duas correntes historiográficas vêm delineando os estudos históricos na contemporaneidade: o Marxismo e a Nova História. Ambas se rivalizam e se encontram dependendo dos recortes temáticos. A rejeição a uma prática descritiva de base positivista as aproximam. Conflitos, confrontos e confluências têm sido uma marca nos últimos anos entre essas duas posições, com olhares mútuos de desconfiança. Nos últimos anos, foram colocados a prova os conceitos do materialismo histórico, bem como as abordagens metodológicas dos Annales. Alguns advogam esse desfecho buscando confluências².

A História "mudou muito de conteúdo", principalmente na forma como ela é vista e trabalhada pelos historiadores de ofício. É claro que depende do momento histórico e do enfoque que é dado à História. Nas últimas décadas costuma-se dizer que a História é formada por diversos campos, constituindo-se em diversas experiências profissionais e acadêmicas.

Nos campos da História, Sociologia e Filosofia, destacamos as formulações de Le Goff, (2013), Nora (1993), Halbwachs (2003) e Ricoeur

\footnotetext{
${ }^{2}$ Em Domínios da História - ensaios de teoria e metodologia?, organizado pelos historiadores Ronaldo Vainfas e Ciro Flamarion Cardoso, importantíssimo para compreender os assuntos metodológicos do trabalho com a História, particularmente com o fazer histórico no Brasil, classifica como Territórios do Historiador, grandes campos: História Econômica, História Social, História e Poder, História das Ideias, História das Mentalidades e História Cultural.
} 
(2007) pela contribuição e enriquecimento dos conceitos de memória, em especial no que se refere a memória social e coletiva - ou como alguns autores atuais preferem chamar, de "memória compartilhada".

Santana (2016) adverte que, mesmo tendo estes autores destaque na pesquisa da memória histórica e social, eles a analisaram embasados na história do seu tempo e suas reflexões e críticas partiram de um conceito prédefinido historicamente. O conhecimento acumulado da História contribuiu então para a formação dos conceitos de memória.

A memória não pode ser considerada um conceito estabelecido e, muito embora os autores citados contribuíram para defini-la em um contexto histórico, as transformações da sociedade agregaram-na novas definições. Nora apresenta uma discussão no início do século XX sobre espaços de memória, concretizando-a sem, no entanto, desconsiderar o simbolismo desse conceito. Parte nesse momento de novas rupturas da memória e abordagens dos estudos desta, não mais como um elemento único, mas, como uma manifestação social.

Enquanto ser social, a sós ou acompanhados, estamos sempre vinculados à sociedade, seja como membro de uma classe, mas simultaneamente estamos ligados a determinados laços ou círculos de convivências. Halbwachs (1877-1945), a partir de suas obras clássicas Quadros sociais da memória (1925) e Memória Coletiva (1952), alude que os estudos da memória deve levar em conta os contextos sociais como baliza na elaboração daquilo que denominamos como sendo memória.

Em se tratando de lembranças jamais estamos sós, sentencia o autor. Isso não significa estar presente fisicamente, mas ao rememorarmos experiências vividas, sempre nos referimos a presença de alguém. Assim, ao longo da vida, fizemos parte de grupos de memória, nos mais diferentes ambientes: família, trabalho, vida social. No processo de reconstituição dos acontecimentos, necessitamos apropriarmos da memória dos outros (2003, p. 39).

A memória individual vive imersa a um coletivo, mediante a uma trama de relações. Ou seja, não existe uma memória por si mesma. Portanto, não é possível, pensar em nós mesmos se não em relação ao(s) outro(s). Sempre recorreremos a alguém ou a um grupo no qual pertencemos.

Neste campo, Halbwachs define a memória individual e coletiva. A primeira pertencente a uma dimensão mais pessoal, de foro íntimo. A segunda designa aquelas recordações que adentram no círculo das preocupações mais comuns ou de interesse mais geral. Todavia, ambas se interpenetram ou se complementam, pois nunca estarão isoladas, pois expressam as marcas do social, isto é, do humano. Muitas vezes temos uma forte tendência de recordar 
aquilo que nos provocou um impacto emocional. Segundo a neurociência, o passado está inteiro em nossa memória, mas em razão dos mecanismos de funcionamento de nosso cérebro, não possibilita que evoquemos todos os detalhes da parte inconsciente.

Não somente em sentido histórico pode-se compreender as diversas facetas da memória, mas também em sua semântica. Acerca disso, Santana (2016) argumenta que é possível com uma simples análise dos dicionários de língua portuguesa conhecer as inúmeras definições para a memória. Ela então - com base em seu sentido semântico - ganha termos polissêmicos e ambíguos em nossa atualidade, abrangendo as mais diversas áreas do conhecimento, inserindo termos e definições na biologia e na informática, por exemplo.

Nora (1993) afirma que a memória é a vida, carregada pelos grupos vivos e neste sentido está em constante evolução, aberta a dialética da lembrança e do esquecimento, não tendo consciência das suas deformações sucessivas e ainda a memória se torna vulnerável as manipulações. $O$ autor outrora alega com base em Hobsbawm que "há tantas memórias quanto grupos existem" e "a memória é um fenômeno sempre atual, um elo vivido sempre no presente". Mais adiante o autor conclui "a árvore da memória e a casca da história" (NORA, 1993, p.09).

Como podemos entender nas afirmações de Nora, que a memória não é a história em si e sim um objeto de estudo desta. Neste caso um recurso que o historiador utiliza na compreensão dos acontecimentos humanos em sociedade. Le Goff indaga que: "Tal como o passado não é a história mas o seu objeto, também a memória não é a história, mas um dos seus objetos e simultaneamente um nível elementar de elaboração histórica" (LE GOFF, 2013, p.49).

É possível considerar a memória humana como uma espécie de aglomerado de pensamentos, guardados, compostos pelos mais diversos sentimentos: são lugares, espaços, pessoas, acontecimentos, traumas, percepções, sons e aromas. Esses sentimentos, reunidos e combinados em uma lembrança aos poucos se transformam em memória: aquela festa de casamento; aquele funeral; aquele acontecimento que reuniu todos na frente da TV. Mas como então reunimos essas memórias e porque a consideramos memórias?

Sendo a memória carregada de sentimentos, Izquierdo (2014) ressalta que os estudos relacionados a neurociência descrevem que eventos traumáticos ou de grande euforia são mais fáceis de recordar, ou seja, todos recordamos por mais tempo e em maior detalhe acontecimentos que ocorreram com um forte grau de alerta emocional. 
Para os estudos da Neurologia, o autor define o termo memória como a aquisição formação, conservação e evocação de informações. Essa aquisição pode ser também chamada de aprendizado ou aprendizagem onde segundo o autor só se pode gravar as informações que forem aprendidas. A evocação dessas memórias é definido como uma espécie de recordação ou melhor definindo, uma lembrança.

Lembramos que não nos cabe aqui o aprofundamento dos conceitos de memória dentro da Medicina, visto que nossa única função é compreender as ramificações da memória dentro da Ciência da História. Porém, rejeitar as contribuições da neurociência na busca por desvendar o cérebro humano e como ele preserva informações seria de certa forma egoísta para nós pesquisadores da história, e, não adentrarmos nesse conhecimento, poderia de certa forma desprimorar a análises de estudo históricos.

Os grupos escolares de medianeira deixaram um legado para as próximas gerações que precisam ser resgatados. Neste contexto, a memória torna-se objeto da pesquisa de fontes dessas instituições, buscando relacionar o passado, o presente e o futuro.

\section{MEMÓRIA E ESQUECIMENTO NA PESQUISA DE FONTES DOS GRUPOS ESCOLARES}

Entender as ações humanas no tempo e no espaço, suas transformações e as alterações que esta executa no ambiente é a função da História, mas como ciência, capaz de analisar os acontecimentos imbricados entre o real e o imaginário. Stephanou e Bastos (2011) vão além e consideram a História como um campo vasto de produção do conhecimento, nutrindo-se das mais diversas teorias, abarcando a análise das fontes, suas relevâncias e dicotomias.

Nesse pensamento, ingressamos nossas considerações sobre as fontes e quais as contribuições que a memória exerce dentro da pesquisa historiográfica de documentos, materiais, orais e quais os cuidados que o pesquisador precisa quando as fontes não dizem ou não querem dizer a totalidade dos fatos, isto é, o esquecimento.

Quando nos referimos a definição de "fontes", cabe-nos apenas o entendimento e a pesquisa das fontes em seu sentido histórico. Nesse caso não se poderia falar sobre as fontes naturais ou como coloca Saviani (2004) as fontes relativas as ciências naturais. Sendo assim, no que se refere a história e a historiografia, as fontes por definição são construídas, são produções humanas de suas transformações no mundo. $O$ autor considera que não se pode tratar as fontes como a origem do fenômeno histórico pois estas estão 
em sua origem, constituindo o ponto de partida para a construção historiográfica e não são em suma a história. Para Saviani:

Assim, as fontes históricas não são a fonte da história, ou seja, não é delas que brota e flui a história. Elas, enquanto registros, enquanto testemunhos dos atos históricos, são a fonte do nosso conhecimento histórico, isto é, é delas que brota, é nelas que se apoia o conhecimento que produzimos a respeito da história (SAVIANI, 2004, p 29, 30).

Outro ponto ressaltante da pesquisa de fontes é a denominação da "fonte" em si. Sendo um objeto construído pela ação humana, ele só pode ser considerado ou melhor, só adquire o título de fonte diante do historiador (SAVIANI, 2004). Diante do problema exposto, o historiador delimitará os elementos e os pressupostos teóricos com base nas questões que o objeto, já considerado por ele em fonte, disponibiliza. As fontes neste caso, não são apenas objetos da pesquisa, mas recortes e delimitações a serem analisadas. No caso das fontes para os estudos da educação o mais correto é delimitar os recortes necessários para a investigação e quais os instrumentos serão abordados na pesquisa.

Silva (2015) calcado em estudo bibliográfico e levantamento em arquivos escolares, pontua alguns elementos históricos acerca da constituição da escolarização em Cascavel. O autor levanta um problema acerca da condição precária dos acervos das escolas tem sido um dos problemas mais observados, consistindo na eliminação indiscriminada dos documentos. Destaca que o conhecimento da documentação visa levar alunos e professores a compreender a importância na reconstrução da memória institucional, chamando atenção para a valorização e preservação das fontes e dos arquivos escolares.

Para Silva (2016) a conexão entre o passado, o presente e o futuro levando em consideração suas manifestações em um determinado período histórico, onde o pesquisador na atualidade interroga as diversas formas de registros situados no presente, propicia diferentes deduções sobre o que as fontes desejam ou não transmitir. Dessa forma, torna-se possível uma análise historiográfica entender a pluralidade de interpretações desses objetos de estudo.

As fontes que preservam o passado relacionam-se com fatos do futuro, possibilitando que novos trabalhos de pesquisam sejam realizados visto que como afirma Silva: "quanto mais fontes forem selecionadas, organizadas e arquivadas, mais oportunidades de compreensão das transformações 
históricas serão oferecidas aos pesquisadores que se propõem a reconstruir a história das instituições escolares" (2016, p.145).

Stephanou e Bastos (2011) asseguram que hoje há uma evidente ruptura nas concepções de que apenas os documentos escritos possuem valor para a pesquisa, principalmente os oficiais.

Quando deixamos de lado o argumento de uma "verdade de documentos", onde apenas alguns documentos escritos são construtores de história, podemos encontrar outros vestígios em fontes que antes eram consideradas contaminadas, tendenciosas. Trata-se das fontes orais, que para muitos historiadores e estudiosos da área não tem a mesma veracidade e autenticidade dos documentos escritos. Ricouer analisa as fontes orais como elos que relacionam a memória escrita e a memória dita. Para ele "Com o testemunho passa-se um processo epistemológico que parte da memória declarada, passa pelo arquivo e pelos documentos e termina na prova documental" (RICOEUR, 2007, p. 170).

Surge uma aceitação da história a partir das memórias plurais, fragmentadas e sem nexo ou como o autor mesmo cita de "testemunhos". É uma produção do conhecimento oriundos de rastros de memórias, incrustadas nos mais sombrios espaços da mente e igualmente concebidas em lembranças e reminiscências, assim como são as experiências vividas e um indivíduo ou em sua coletividade.

Silva (2016) assinala que a preservação das fontes dessas instituições ganha notoriedade quando inseridas dentro de um contexto social e histórico, trazendo manifestações de grupos sociais específicos. Isso torna relevante a compreensão da história da educação de uma sociedade, visto que os grupos sociais e as fontes escolares estão intrinsecamente relacionando.

O esquecimento, em consonância com a memória, surge na pesquisa das fontes das instituições de ensino como um aviso do descaso do governo e das próprias instituições de ensino quanto a preservação dos documentos. É possível ver, quando adentramos em almoxarifados e arquivos de escolas as condições precárias de conservação dos documentos que contam suas origens, quando existem documentos a serem guardados.

Le Goff (2013), faz uma advertência aos historiadores quando estes se deparam com o esquecimento das fontes. Para ele é preciso escrever a história do que não existe ou que de alguma forma foi esquecido ou manipulado. Se há lacunas na história, dessa maneira, sendo intencionais ou não, devem ser historiadas:

Falar dos silêncios da historiografia tradicional não basta; penso que é preciso ir mais longe: questionar a documentação histórica sobre as 
lacunas, interrogar-se sobre os esquecimentos, os hiatos, os espaços brancos da história. Devemos fazer o inventário dos arquivos do silêncio, e fazer a história a partir dos documentos e das ausências de documentos (LE GOFF, 2013, p. 109).

Por fim, consideramos que a importância da pesquisa de fontes e arquivos escolares não limita-se aos interesses do meio científico, devendo estender-se a toda a comunidade. É de suma importância que a sociedade compreenda, conheça e preserve sua memória educacional, reconhecendo a escola como um espaço de memória e um patrimônio histórico e cultural. Quando a pesquisa alcança a sociedade, ela deve ser entendida como um compromisso diária de preservação desse patrimônio, onde pesquisadores e agentes escolares devem garantir a manutenção e cuidado com as fontes historiográficas da escola.

\section{OS GRUPOS ESCOLARES DE MEDIANEIRA}

A priori, as fontes documentais dos grupos escolares de Medianeira encontram-se espalhadas entre arquivos públicos e particulares. Em arquivos municipais, os obstáculos para a reunião das fontes são diversos. Essas instituições iniciaram suas atividades no início da década de 1950, quando Medianeira era apenas uma comunidade formada por imigrantes sulistas. Logo torna-se distrito de Foz do Iguaçu pela Lei no 99, de 31 de julho de $1952^{3}$. Medianeira torna-se município, desmembrando suas funções administrativas de Foz do Iguaçu pela Lei Estadual no 4245, de 25 de julho de $1960^{4}$. No entanto, na década de 1970, um incêndio na prefeitura acarretaria na perda da maioria dos arquivos e documentos.

Os poucos registros disponíveis dos grupos escolares de Medianeira foram encontrados em arquivos particulares de pioneiros e personagens que integraram essas escolas. Dentre os documentos encontrados, estão as nomeações de professores, relatos escritos e algumas fotografias.

\footnotetext{
${ }^{3}$ Art. 10 Fica o Poder Executivo autorizado a criar distritos no Município de Foz do Iguaçu.

Art. 2 As novas Vilas denominar-se-ão: "Gaúcha", "Medianeira" e "Matelândia".

${ }^{4}$ Art. 4ํ Fica criado o município de São Miguel do Iguaçu, desmembrado dos municípios de Foz do Iguaçu e Medianeira, sede na localidade do mesmo nome e divisas seguintes:

Anexo I - Com o município de Medianeira: começa no rio Paraná, na foz do rio São Vicente, sobe por este até a foz do arroio São João e este até a sua cabeceira, donde em reta, por uma linha seca, alcança a cabeceira de seu contra afluente, o qual desce até a sua foz no rio Ocoí e este até a foz do arroio Laranjinha, o qual sobe até a sua cabeceira, donde em reta, por uma linha seca alcança a cabeceira do arroio Charrua, o qual desce até a sua foz no rio Represa Grande e este até a sua foz no rio Iguaçu;
} 
Em 1996, a Associação dos Professores Aposentados de Medianeira (APAM), publicou o livro "O Resgate da Memória de Medianeira" onde pesquisou-se em depoimentos e relatos e a história da colonização do município. Nele é possível conhecer - de forma preliminar - a criação e a rotina do primeiro grupo escolar: O Grupo Escolar Miguel Matte.

Elza Biesdorf, coordenadora do projeto, relata no livro como foi ser a primeira professora a lecionar na cidade. Seu relato de pouco mais de duas páginas é, até o momento, contribuição importante para a preservação da memória do primeiro grupo escolar do município.

A constituição da primeira instituição de ensino ocorreu em 1952, dois anos após as primeiras famílias chegarem ao território demarcado pela Companhia Colonizadora Bento Gonçalves, responsável pela compra e venda das terras aos pioneiros, em sua maioria imigrantes ou filhos de imigrantes italianos e alemães oriundos dos estados do Rio Grande do Sul e de Santa Catarina. Nesse período, Medianeira ainda era um enorme território de mata derrubada, cheiro de fumaça e casas de madeira espalhadas entre toras e plantações (DE PAULA; SILVA, 2018, p. 159).

Figura 1: Grupo Escolar Miguel Matte, 1952. Construído pela Colonizadora Bento Gonçalves, dispunha de 2 salas de aula e atendia os filhos dos pioneiros de medianeira

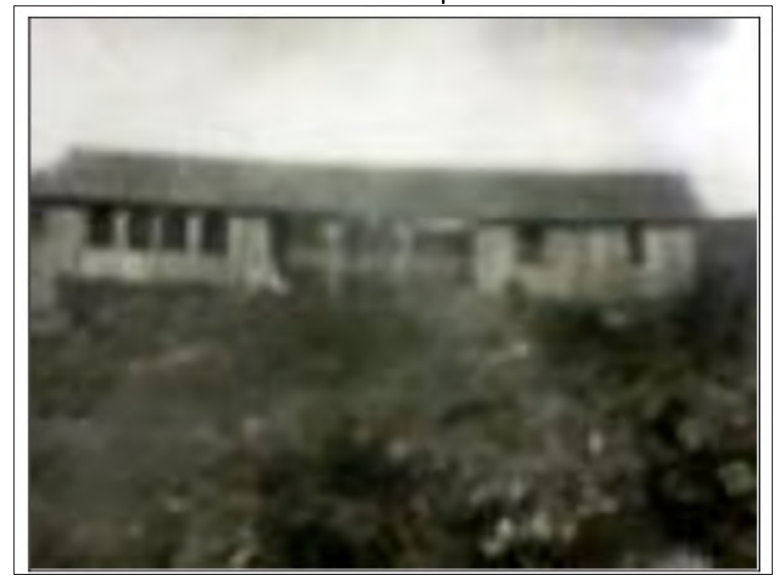

Fonte: Hilegarde Maria Rohde

Os primeiros meses de ensino do Grupo Escolar Miguel Matte ocorreram nas dependências da igreja Católica da comunidade. A estrutura religiosa não comportava um ensino de qualidade, visto que não haviam carteiras. As aulas eram ministradas em uma grande mesa onde os alunos se reuniam e tomavam as primeiras lições de letras e números. Os alunos eram ensinados em grupo, não havendo possibilidade de ensino diferenciando para 
aqueles que já possuíam alguma escolaridade ou para aqueles que ainda não tinham sido alfabetizados. Era uma situação provisória e emergencial para suprir as necessidades de educação dos filhos dos pioneiros.

Figura 2: Decreto n. 80 de 1a de setembro de 1952 no qual nomeou a senhora Elza Biesdorf ao cargo de professora do Grupo Escolar Miguel Matte

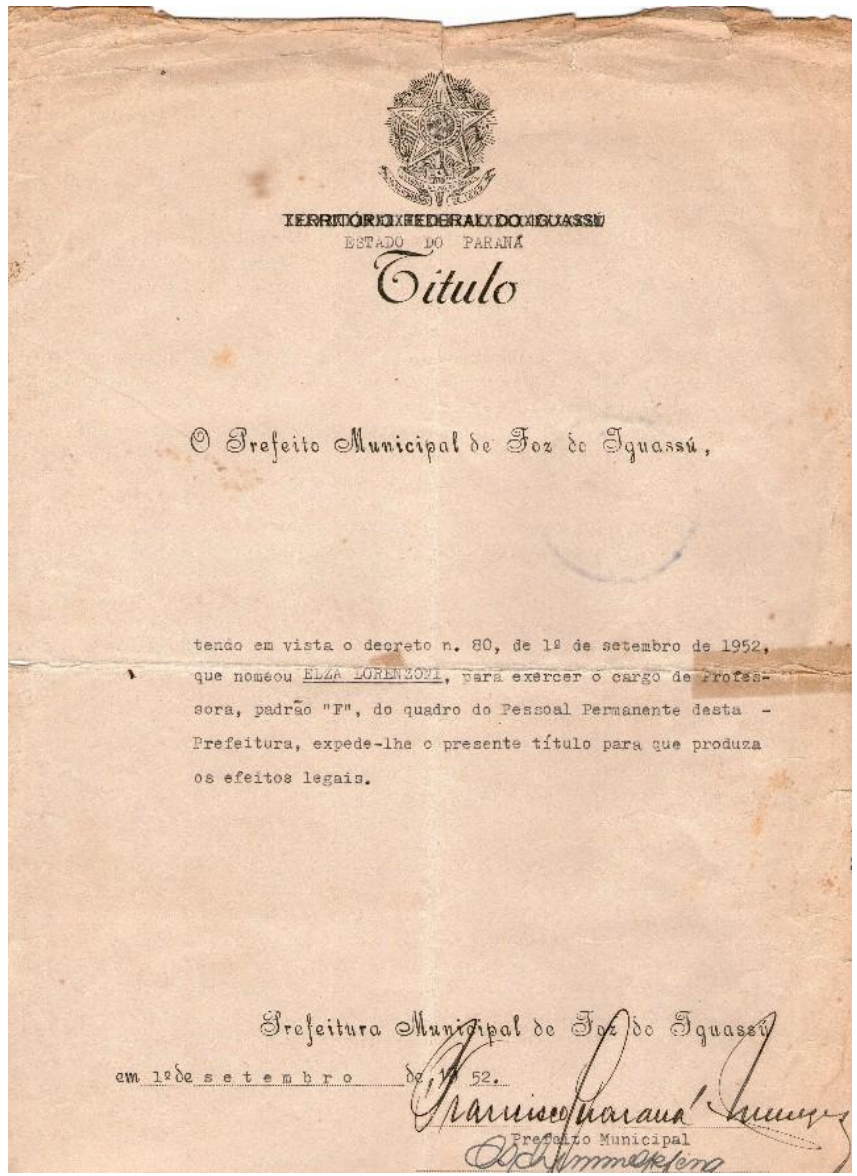

Fonte: José Biesdorf

As primeiras manifestações educacionais contaram com a ajuda da Igreja que, de alguma forma, estava ligada a educação. Saviani (2004) cita que no Brasil houve a participação da Igreja e da família no meio educacional, em muitos casos precursoras da escola, atuando direta ou indiretamente no interior dessas instituições. Não se pode dizer que há uma intencionalidade quanto a supremacia da Igreja ou da família no ambiente educativo, mas a 
princípio, consideramos - no caso específico dos Grupos Escolares em Medianeira - de uma preocupação quanto a educação dos menores.

Figura 3: Professora Elza Biesdorf com alunos no Grupo Escolar Miguel Matte, na Igreja Católica de Medianeira onde as primeiras aulas foram ministradas

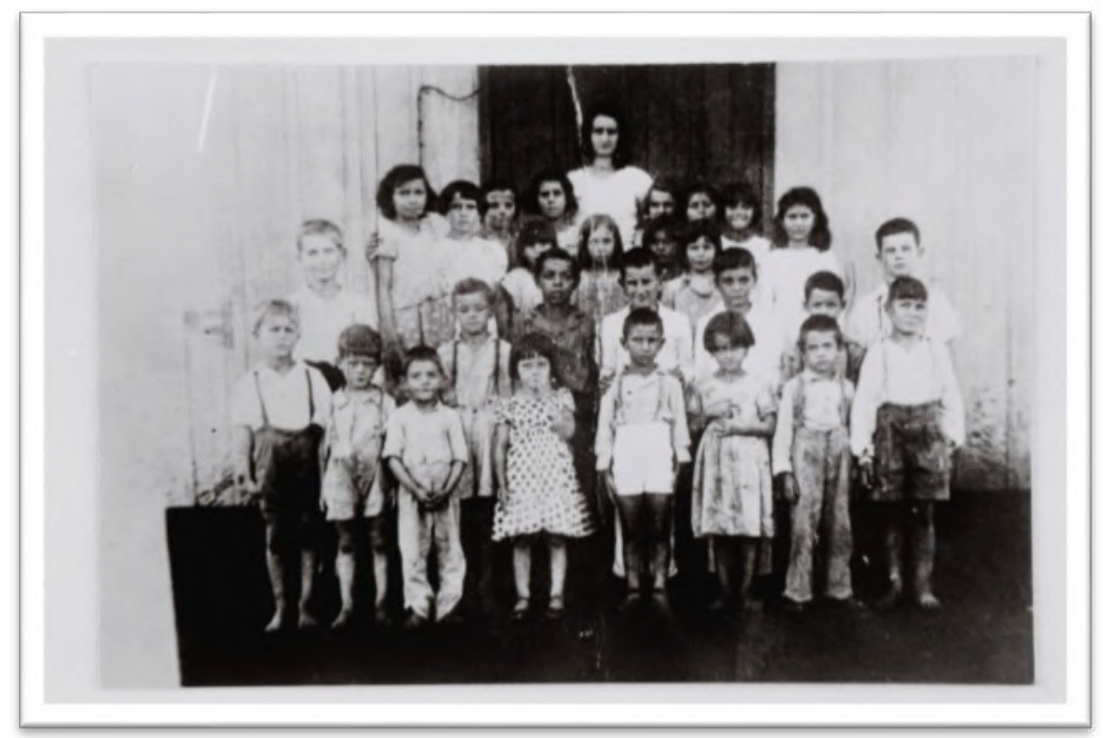

Fonte: Livro "O Resgate da Memória de Medianeira".

Vendo a necessidade de uma estrutura que oferecesse qualidade de ensino aos alunos, a Companhia Colonizadora Bento Gonçalves construiu em 1953, a primeira dependência física da instituição, com duas salas de aula, carteiras novas e quadro-negro (BIESDORF; ROHDE, 1996). O ensino que deveria ser multisseriado não aconteceu devido à falta de professores. Eram ministradas aulas para o primeiro, segundo e terceiro ano simultaneamente, com cartilhas separadas, oferecidas a professora Elza Biesdorf pela Prefeitura de Foz do Iguaçu. Mais tarde, com o aumento dos alunos, foram contratados mais dois professores. O Grupo Escolar Miguel Matte foi extinto em 1955, com a criação do Educandário Nossa Senhora de Medianeira, sendo os alunos transferidos para esta instituição.

São evidentes as lacunas existentes na pesquisa dos grupos escolares de Medianeira, porém, os primeiros apontamentos já contribuem para definir que tanto a Igreja e o governo quanto os pioneiros, tinham a preocupação com o acesso à educação. Do mesmo modo, é preciso perceber que o processo de constituição da escola durante a colonização da região Oeste do Paraná não foi homogêneo, mas como aponta Emer, possuiu traços gerais: "O grupo escolar 
que a primeira vista poderia representar um salto qualitativo para a educação regional, significou mais a presença do poder do Estado e uma diluição da relação da sociedade com sua escola, que o Estado a serviço daquela formação social" (1991, p.241).

Mesmo com o interesse do Estado na educação, singularmente o Grupo Escolar Miguel Matte ainda contou com a ajuda da comunidade de pioneiros e com a Colonizadora Bento Gonçalves nos poucos anos de sua existência. O Governo neste caso, contribuiu apenas com a contratação dos professores, cabendo a Colonizadora a doação do terreno e a construção da estrutura educacional. Houve uma ajuda mútua na criação e manutenção dessa escola, que apesar de iniciar a educação no município, não se consolidou.

\section{CONSIDERAÇÕES FINAIS}

Diante do exposto, faz jus a reflexão da importância e preservação das fontes e arquivos que guardam a história da educação regional. Abarcar a memória como objeto norteador da pesquisa historiográfica torna o trabalho do historiador fundamentado socialmente. Outro fator que precisa ser explanado é a postura do pesquisador diante do esquecimento, visto que em muitos casos, a história está presente também naquilo que não está sendo dito. A pesquisa dos grupos escolares neste sentido, ganha o apoio dos historiadores da História da Educação, da pesquisa das fontes e no compromisso com a sociedade.

Faz-se necessário a relação de comprometimento do historiador com as fontes, tendo em vista que o trabalho por vezes é árduo e cansativo. Pesquisar a constituição dos grupos escolares na Região Oeste, analisando os determinantes políticos, sociais e econômicos que influenciaram na formação dessas instituições abre caminhos para novas investigações, contribuindo para as pesquisas em História da Educação.

Fomentar as discussões a respeito dessa modalidade de ensino, que, apesar de ter ganho espaço expressivo dentro do meio acadêmico nas últimas décadas ainda é um campo pouco explorado. Este esforço abre indagações que propiciam novas investigações referentes ao processo de desenvolvimento social e educacional dessas instituições e possibilitam um diálogo entre a academia e a comunidade. 


\section{REFERÊNCIAS}

BIESDORF, Elza; ROHDE, Hilegarde Maria. O Resgate da Memória de Medianeira. Curitiba, CEFET, 1996.

DE PAULA, Sander Fernando; SILVA, João Carlos da; História e Memória no Oeste Paranaense: estudo preliminar sobre os Grupos Escolares de Medianeira (1952-1964). In: BUENO, André; CREMA, Everton; ESTACHESKI, Dulceli; NETO, José [org.] Aprendizagens Históricas: história do ensino. União da Vitória/Rio de Janeiro: LAPHIS/Edições especiais Sobre Ontens, 2018. E-Book. ISBN 978-8565996-55-6. Disponível em:

https://www.academia.edu/36491107/Aprendizagens_Hist\%C3\%B3ricas_Hist \%C3\%B3ria_do_Ensino. Acesso em: 10 jul. 2018.

EMER, Ivo Oss. Desenvolvimento histórico do Oeste do Paraná e a construção da escola. Rio de Janeiro: Dissertação de Mestrado. FGV, 1991.

HALBWACHS, Maurice. A memória coletiva. São Paulo: Centauro, 2003.

IZQUIERDO, Iván. Memória [recurso eletrônico] / Iván Izquierdo. - 2. ed. rev. e ampl. - Porto Alegre: Artmed, 2014.

LE GOFF, Jacques. História e memória. Campinas, SP: Editora da Unicamp, 2013.

NORA, Pierre et al. Entre memória e história: a problemática dos lugares. Projeto História: Revista do Programa de Estudos Pós-Graduados de História, v. 10, 1993.

SANTANA, Dorival Aparecido de. A escola como lugar de memórias e de identidades: um estudo a partir de escritos de alunos do ensino médio do Colégio E. N. S. de Lourdes - Londrina/PR.2013-2014. 2016. 332 fls. Dissertação (Mestrado em História Social) - Universidade Estadual de Londrina, Londrina.

SAVIANI, Demerval. Breves considerações sobre fontes para a história da educação. In: LOMBARDI, José C.; NASCIMENTO, Maria Isabel Moura. Fontes, história e historiografia da educação. Campinas. Autores Associados, 2004.

SILVA, João Carlos da. História e Memória na Região Oeste do Paraná: Fontes e Arquivos. Cadernos de Pesquisa: Pensamento Educacional, Curitiba, v. 11, n. 27, p.133-148 jan./abr. 2016.

SILVA, João Carlos da. História e memória educacional na região oeste do Paraná. Interfaces Científicas - Educação, v. 4, p. 87-100, 2015. 
STEPHANOU, Maria; BASTOS, Maria Helena Câmara. História, Memória e História da Educação. In: STEPHANOU, Maria; BASTOS, Maria Helena

Câmara. Histórias e memórias da educação no Brasil - Vol. III: Século XX.

Petrópolis, RJ: Editora Vozes, 2011.

RICOEUR, Paul, 1913. A memória, a história, o esquecimento. Campinas, SP:

Editora da Unicamp, 2007. 